\title{
The Evaluation of the Metabolic-inhibition Technique for the Study of Mycoplasma gallisepticum
}

\author{
By D. TAYLOR-ROBINSON \\ Clinical Research Centre, Harvard Hospital, Salisbury, Wiltshire \\ AND D. M. BERRY \\ Glaxo Laboratories Ltd., Greenford, Middlesex
}

(Accepted for publication 3 September 1968)

\section{SUMMARY}

Antisera to nine strains of Mycoplasma gallisepticum were prepared in rabbits, chickens and turkeys, the response of individual rabbits or birds varying widely. Minor antigenic differences between some of the strains were shown in metabolic inhibition (m.i.) tests with rabbit antisera. The strains could be divided into at least three subtypes. In general, antibody diminished so that it was barely detectable 6 months after inoculation.

Antibody titres measured by m.i. were lower in chicken and turkey antisera than in rabbit antisera. The choice of the mycoplasma strain to be used in the m.i. test for the measurement of antibody in the bird sera was of fundamental importance since not all strains were capable of detecting antibody; strain T37 was the most useful.

Antibody measured by m.i. was not destroyed by repeated freezing and thawing of antisera, and the antibody titres were not, in general, increased by the addition of unheated guinea-pig serum to the tests. The titres of antibody which inhibited metabolism of the mycoplasma strains were closely similar to those which inhibited their growth in liquid medium. On solid medium, however, some rabbit antisera with high m.i. antibody titres did not inhibit or inhibited poorly the development of colonies of the homologous strains. Only one of the nine rabbit antisera inhibited the development of colonies of all the strains, a feature of importance in mycoplasma identification.

\section{INTRODUCTION}

Agglutination (Adler, 1953) and haemagglutination inhibition (Jungherr, Luginbuhl \& Jacobs, 1953) have been the serological techniques used most extensively for the study of mycoplasmas from birds. Growth inhibition by antiserum incorporated into agar medium was used by Edward \& Kanarek (1960), by Fabricant (1960), and more recently by Dierks, Newman \& Pomeroy (1967) for the classification of mycoplasmas of avian origin. This method is relatively insensitive compared to the technique of metabolic inhibition (Taylor-Robinson, Purcell, Wong \& Chanock, 1966) which has been used to detect minor antigenic differences betwen mycoplasmas within one serotype (Purcell et al. 1967). This paper reports on the use of the metabolic inhibition technique for the antigenic study of Mycoplasma gallisepticum strains. In addition, other factors, such as the use of a particular strain for measuring antibody and the possible requirement for unheated guinea-pig serum, have been evaluated and 
results obtained by metabolic inhibition have been compared with those obtained by growth inhibition in liquid and on agar media.

\section{METHODS}

Mycoplasma strains. Mycoplasma gallisepticum strains T34, T37, MG2, C54, JI and A5I4, isolated from field infections in this country, were obtained from Dr D. H. Roberts, Dr F. T. W. Jordan and Dr A. G. Newnham. Strains s6 and A5969, isolated in the U.S.A., were obtained from Dr D. H. Roberts. The prototype strain X95 (Edward \& Kanarek, 1960) was obtained from Dr R. H. Leach.

Media. The media (A) used at Glaxo Laboratories were Brucella broth and agar described by Newnham (1964). The liquid and solid media (B) used in Salisbury were basically those described by Hayflick (1965), and have been reported previously (Manchee \& Taylor-Robinson, 1968).

Antigen production. All strains were cloned three times on medium A except strains s6 and C54 which were cloned on medium B. Thereafter, organisms to be used for metabolic inhibition and disc-growth inhibition tests were grown in liquid medium $\mathbf{A}$ by incubating at $37^{\circ}$ until the medium $\mathrm{pH}$, initially $7 \cdot 8$, decreased by at least one unit. The cultures were then divided into lots, stored at $-70^{\circ}$ and a sample titrated by the 'colour-change' technique (Taylor-Robinson \& Purcell, 1966) for its content of viable organisms. One colour-changing unit (c.c.u.) of activity was defined as the highest dilution which produced a colour change. Antigens for rabbit and bird inoculation were prepared from organisms propagated in a similar manner; organisms were concentrated I00-fold by centrifugation at $10,000 \mathrm{rev} . / \mathrm{min}$. for $20 \mathrm{~min}$. and resuspension in phosphate-buffered saline. These antigens were then inactivated by incubation with $\mathrm{I} / 1000 \beta$-propiolactone for $2 \mathrm{hr}$ at $37^{\circ}$.

Antiserum production. Antisera were prepared in groups of rabbits and 6-week-old Mycoplasma gallisepticum-free chickens and turkeys. Each of these was inoculated intramuscularly with $0.5 \mathrm{ml}$. of inactivated antigen and this procedure was repeated I4 days later. In addition, each chicken and turkey was inoculated intrathoracically with $10^{8}$ c.c.u. of the homologous viable mycoplasma 28 days after the first inoculation. Sera were obtained before inoculation, 28 days after the first inoculation and at weekly intervals thereafter. They were stored at $-20^{\circ}$ and were inactivated at $56^{\circ}$ for $30 \mathrm{~min}$. before use.

Guinea-pig serum (g.p.s.). This was obtained from animals killed without anaesthesia. The serum was separated immediately and was stored without preservatives at $-70^{\circ}$.

Metabolic inhibition (m.i.) tests. These were done in Linbro Disposo-trays (ISMRC-96; Linbro Chemical Co. Inc., New Haven, Connecticut, U.S.A.) as described previously by Taylor-Robinson et al. (1966) with liquid media A and B. Unheated g.p.s. was not used unless otherwise stated. The trays were incubated at $37^{\circ}$ for $15 \mathrm{~min}$. before they were sealed at this temperature with sellotape. This prevented detachment of the sellotape from the trays that otherwise sometimes occurred on incubation. The results were recorded when a colour change of about half a $\mathrm{pH}$ unit had occurred in the controls containing mycoplasma organisms but no antiserum.

Disc growth inhibition (g.i.) tests. These were done as described previously by Clyde (I964) using solid medium B. Stock cultures, previously titrated, were diluted in liquid medium so that $0.1 \mathrm{ml}$. contained about $10^{5}$ c.c.u. This was spread on the agar 
medium. Then filter-paper discs of $7 \mathrm{~mm}$. diameter, soaked with $0.025 \mathrm{ml}$. of undiluted antiserum, were placed on the agar. Zones of inhibition were measured from the edge of the disc to the edge of colony development after incubation of the cultures at $37^{\circ}$ in a humid atmosphere of $95 \%(\mathrm{v} / \mathrm{v}) \mathrm{N}_{2}+5 \%(\mathrm{v} / \mathrm{v}) \mathrm{CO}_{2}$.

\section{RESULTS}

Effect of age of culture on the m.i. test. It was considered that the age of the culture used as inoculum in the m.i. test might affect the result. Therefore, the A5969 strain of Mycoplasma gallisepticum was grown in liquid medium B, and at 4 times over a period of I I $8 \mathrm{hr}$ a sample was harvested and stored at $-70^{\circ}$. The samples were titrated for viable organisms; a variation between $10^{4}$ and $10^{9}$ c.c.u. $/ \mathrm{ml}$. occurred. Then each sample was diluted so that when used as inoculum in the m.i. test it contained $1 \mathrm{O}^{3}-\mathrm{IO}^{4}$ c.c.u. The m.i. titre of a rabbit antiserum did not vary more than four-fold (I/2560$\mathrm{I} / \mathrm{I} 0,240$ ) when tested with the four different inocula. Thus, variations greater than this in subsequent experiments were unlikely to be due to the use of cultures of different age. Nevertheless, as described in Methods, some standardization was achieved by harvesting organisms of each $M$. gallisepticum strain when the $\mathrm{pH}$ of the medium had fallen at least one unit, at which time the culture contained at least $10^{8}$ c.c.u. $/ \mathrm{ml}$.

Table I. M.i. tests with rabbit antisera to Mycoplasma gallisepticum strains

\begin{tabular}{|c|c|c|c|c|c|c|c|c|c|}
\hline \multirow{3}{*}{$\begin{array}{c}\text { Antiserum* } \\
\text { to strain }\end{array}$} & \multicolumn{9}{|c|}{ M.i. titre with mycoplasma strain } \\
\hline & \multicolumn{5}{|c|}{ Subtype I } & \multirow{2}{*}{$\begin{array}{c}\text { Sub- } \\
\text { type } 2 \\
\text { A514 }\end{array}$} & \multicolumn{3}{|c|}{ Subtype 3} \\
\hline & T34 & T37 & A5969 & s6 & x95 & & JI & MG2 & C54 \\
\hline T34 & 5,120 & 2,560 & 1,280 & I,280 & 1,280 & 320 & 80 & 320 & 160 \\
\hline T37 & 10,240 & 10,240 & 5,120 & 2,560 & 2,560 & 640 & 80 & 640 & 320 \\
\hline A5969 & 10,240 & 5,120 & 5,120 & 2,560 & 5,120 & 640 & 80 & 160 & 160 \\
\hline s6 & 1,280 & 1,280 & 640 & 640 & 1,280 & 160 & 40 & 80 & 320 \\
\hline x95 & 2,560 & 10,240 & $\mathrm{I}, \mathbf{2 8 0}$ & 2,560 & 20,480 & 640 & 160 & 640 & 320 \\
\hline A5I 4 & 160 & 320 & 160 & 160 & 320 & 2,560 & 80 & 160 & 320 \\
\hline $\mathbf{J I}$ & 320 & 320 & 80 & 160 & 640 & 320 & 5,120 & 320 & 320 \\
\hline MG2 & 160 & 160 & 40 & 80 & 320 & 160 & 320 & 320 & 160 \\
\hline
\end{tabular}

\section{M.i. tests with rabbit antisera}

The antisera prepared against each mycoplasma strain were tested against all the strains in one test (Table I). Strains T34, T37, A5969, s6 and X95 were closely related to one another (subtype 1). Strain A5I4 (subtype 2) was different from subtype I strains, because antisera to subtype I strains inhibited strain A5I4 4- to I6-fold less than they inhibited their homologous strains within subtype I. In addition, antiserum to strain A514 inhibited the other strains 8- to 16-fold less than it inhibited its homologous organism. Strain JI (subtype 3) was different from all the other mycoplasma strains. Antisera to the other strains were 64- to I28-fold less effective in inhibiting strain $\mathrm{JI}$ than in inhibiting their homologous strains, and $\mathrm{JI}$ antiserum was 16 - to 64-fold more active against its homologous strain than against the other strains. Strain MG2 was similar to strain A514 in its reaction to the other antisera but it was probably different 
from strain A5I4; A5I4 antiserum inhibited its homologous organism I6-fold more than it inhibited strain MG2. Although antiserum to strain C54 was not available, this strain behaved in a similar way to strain MG2 in its reaction to the other antisera. These results were confirmed in $\mathrm{m}$.i. tests in which three other antisera prepared against each strain were tested. It was thus apparent that on this basis Mycoplasma gallisepticum comprised at least three serological subtypes.

Duration of antibody persistence. Antisera obtained I, 2 and 6 months after inoculation of rabbits with the 6 strain were tested against this strain and against heterologous strains. The m.i. antibody titres at 2 months were between 4- and 50-fold lower than at I month, the decline being least in tests with the homologous organism. By 6 months the antibody titres had fallen to barely detectable levels.

Table 2. M.i. tests with chicken antisera to Mycoplasma gallisepticum strains

\begin{tabular}{|c|c|c|c|c|c|c|c|c|c|}
\hline \multirow{2}{*}{$\begin{array}{c}\text { Antiserum* } \\
\text { to strain }\end{array}$} & \multicolumn{9}{|c|}{ M.i. titre $\nmid$ with mycoplasma strain } \\
\hline & T34 & T37 & A5969 & s6 & X95 & A5I4 & JI & MG2 & C54 \\
\hline T34 & 16 & 64 & 4 & 64 & $<2$ & $<2$ & $<2$ & $<2$ & 2 \\
\hline T37 & I 6 & 64 & 4 & 64 & $<2$ & $<2$ & $<2$ & $<2$ & 2 \\
\hline A5969 & 8 & 32 & 8 & 16 & 2 & $<2$ & $<2$ & $<2$ & 2 \\
\hline s6 & 8 & 64 & 8 & 32 & $<2$ & $<2$ & $<2$ & 2 & 2 \\
\hline X95 & 8 & 64 & 4 & 32 & $<2$ & $<2$ & $<2$ & $<2$ & $<2$ \\
\hline A5I 4 & 16 & 128 & 8 & 64 & 2 & 4 & 16 & 2 & 4 \\
\hline JI & 8 & 32 & 4 & 8 & 2 & $<2$ & 16 & 4 & 2 \\
\hline MG2 & 8 & 16 & 8 & 16 & 4 & $<2$ & 16 & 4 & 2 \\
\hline C54 & $<2$ & 8 & $<2$ & $<2$ & $<2$ & $<2$ & $<2$ & $<2$ & $<2$ \\
\hline
\end{tabular}

* Prepared by inoculating on day 0 and 14 , challenging with viable organisms on day 28 and bleeding 14 days later.

$\dagger$ M.i. titre of all pre-inoculation sera $<2$.

\section{M.i. tests with chicken and turkey antisera}

Effect of different strains on detection of antibody. Antisera obtained 2 weeks after intrathoracic inoculation of chickens and turkeys were studied. The results of crosstesting all the strains against one of several chicken antisera prepared against each strain are shown in Table 2. Antibody was measured successfully in tests in which strains T34, T37, A5969 and s6 were used; strain T37 was most useful for this purpose. Antibody was detected infrequently or not at all when the antisera were tested with the other mycoplasma strains, even though the strain used in the m.i. test was the same as that which had been used to prepare the chicken antiserum. In addition, when antibody was detectable, subjection of the antisera to nine cycles of freezing and thawing did not diminish their antibody titres in tests with strain T37.

It may be noted that the titre of antibody in chicken antisera was at least 16-fold lower than observed with the corresponding rabbit antisera. In addition, it was not possible to subtype the various mycoplasma strains by using chicken antisera.

The results of testing all the strains against one of several turkey antisera prepared against each strain were similar to the results obtained with the chicken antisera, except that the antibody titres were generally 2 - to 4 -fold greater with turkey antisera.

Variation in antibody response. Several chicken antisera prepared against the s6 strain were tested against both homologous and heterologous mycoplasma strains. The wide variation in antibody response of the different chickens is shown in Fig. I. 
The results of similar tests with several turkey antisera prepared against the s6 strain are shown in Fig. 2. They are similar to those obtained with chicken antisera since wide variations occurred in the titre of antibody in the sera of different birds given the same course of inoculations of a particular strain, and antibody in both chickens and turkeys was best detected by using strains T34, T37, A5969, s6 and X95,

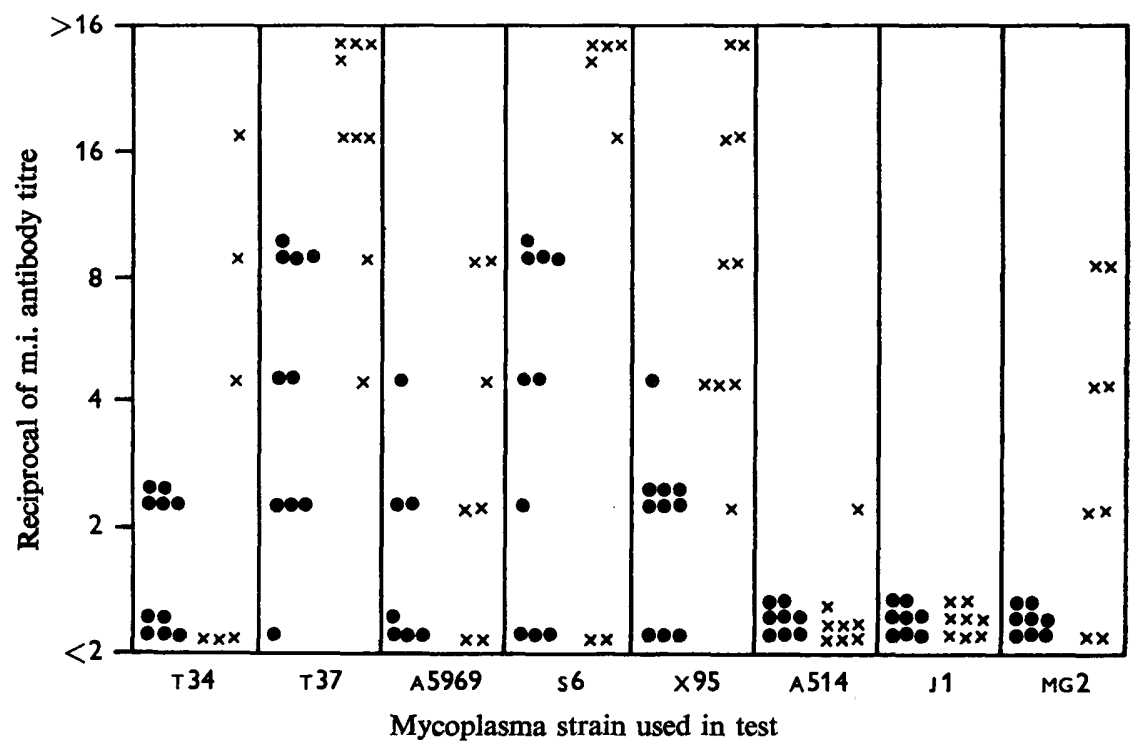

Fig. I. M.i. titres of antisera from chickens inoculated with Mycoplasma gallisepticum strain $\mathbf{5 6}$. Sera taken after inoculation with inactivated antigen $(\bullet)$ and inactivated antigen and viable organisms $(x)$.

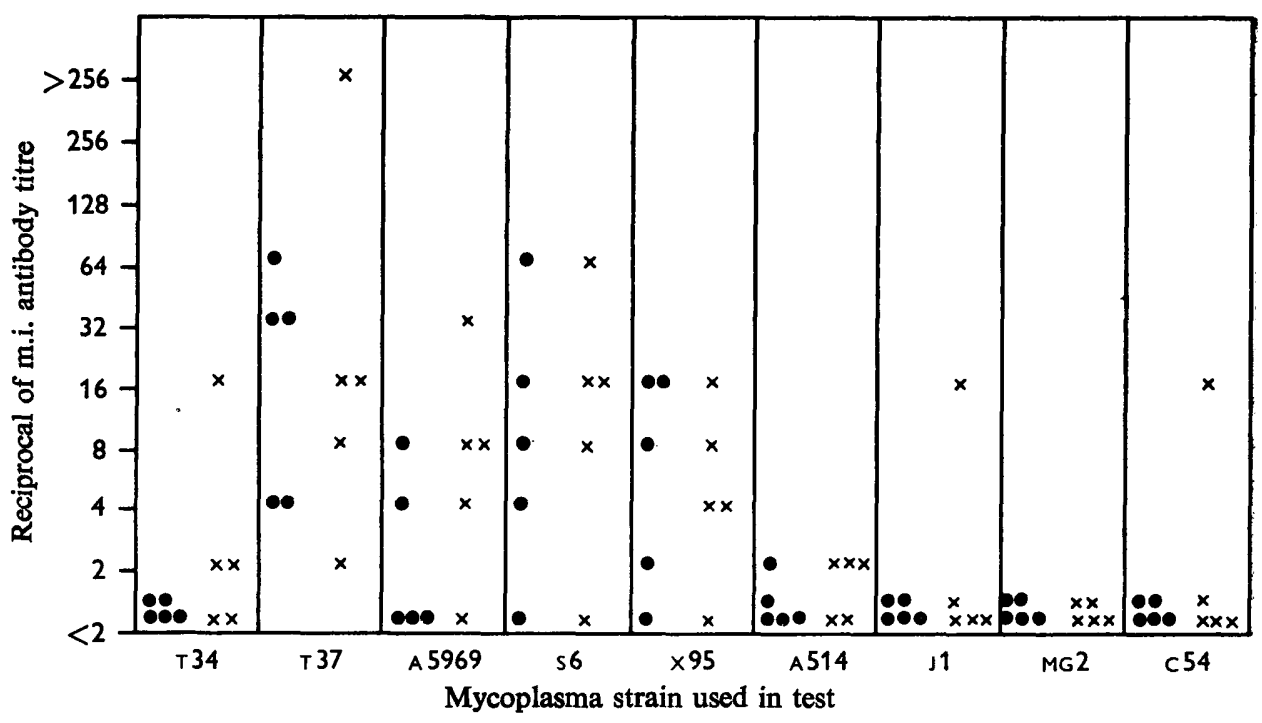

Fig. 2. M.i. titres of antisera from turkeys inoculated with Mycoplasma gallisepticum strain s6. Sera taken after inoculation with inactivated antigen $(\bullet)$ and inactivated antigen and viable organisms $(x)$. 
The use of unheated g.p.s. in the m.i. test

Previous results (Taylor-Robinson et al. 1966; Purcell et al. 1967) indicated that an accessory factor, such as unheated g.p.s., might be essential to demonstrate antibody or be required to enhance the antibody titre in the m.i. test.

Effect of unheated g.p.s. on mycoplasma growth. Since unheated g.p.s., in the absence of antiserum containing antibody, was known to inhibit the growth of some mycoplasmas, all the strains under study were titrated in the absence and in the presence of $10 \%$ unheated g.p.s. in the medium. Two strains were titrated also in medium containing $10 \%$ g.p.s. which had been heated at $56^{\circ}$ for $30 \mathrm{~min}$. The results are shown in Table 3. The growth of some strains was inhibited by unheated g.p.s., whereas the growth of others was unaffected. Those strains most inhibited by unheated g.p.s. were those which were found previously to be most suitable for the detection of $\mathrm{m}$.i. antibody in chicken and turkey sera. Heated g.p.s. did not inhibit the growth of the two strains tested.

Table 3. Inhibition of growth of Mycoplasma gallisepticum strains by $10 \%$ guinea pig serum (g.p.s.)

$\begin{array}{lccc}\begin{array}{c}\text { Mycoplasma } \\ \text { strain }\end{array} & \begin{array}{c}\text { Initial titre } \\ \left(\log _{10}\right) \text { of } \\ \text { viable } \\ \text { organisms }\end{array} & \overbrace{\text { Unheated }}^{\text {geduction in titre }\left(\log _{10}\right) \text { by }} & \begin{array}{c}\text { Heated } \\ \text { g.p.s. }\end{array} \\ \text { T34 } & 9 & 3 & \text { n.t. } \\ \text { T37 } & 9 & 3 & \text { n.t. } \\ \text { A5969 } & 8 & 4 & \text { Nii } \\ \text { S6 } & 8 & 4 & \text { Nil } \\ \text { X95 } & 9 & \text { Nil } & \text { n.t. } \\ \text { A5I4 } & 8 & \text { Nil } & \text { n.t. } \\ \text { JI } & 9 & 2 & \text { n.t. } \\ \text { MG2 } & 9 & \text { Nil } & \text { n.t. } \\ & \text { n.t. }=\text { not tested. } & \end{array}$

Table 4. Effect of guinea pig serum (g.p.s.) on the m.i. titre of rabbit and chicken antisera

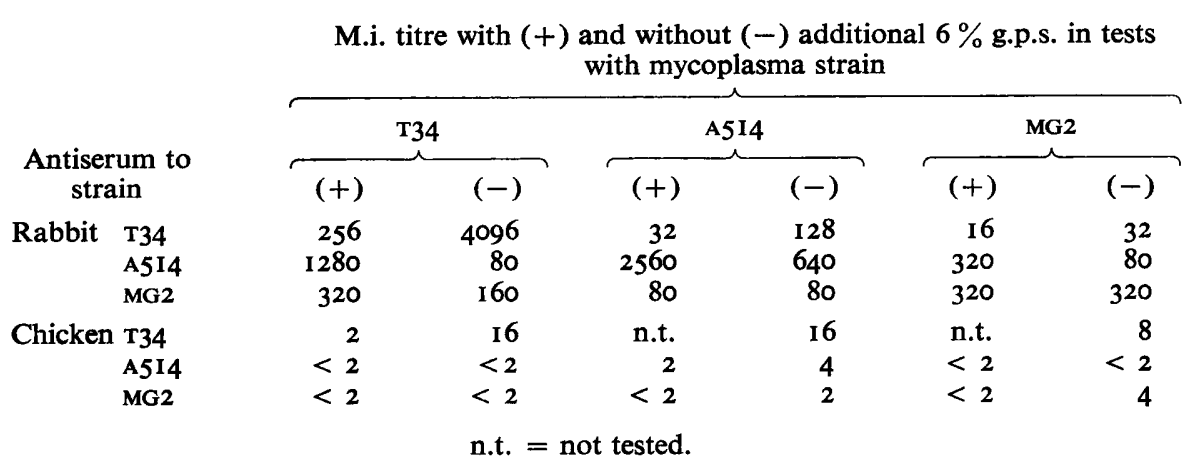

Effect of unheated g.p.s. on the m.i. antibody titre. The results which have been presented were obtained in tests done without unheated g.p.s. However, all the rabbit antisera and most of the chicken antisera were tested also with additional unheated 
g.p.s. and some of the results are shown in Table 4. With few exceptions, notably strain A5I4 tested against rabbit antisera, the addition of unheated g.p.s. did not enhance the m.i. antibody titre and sometimes it depressed the titre. However, it was found that unheated g.p.s. stabilized the m.i. titre in some instances (not shown in Table); in other words, in the absence of unheated g.p.s., colour changes that occurred

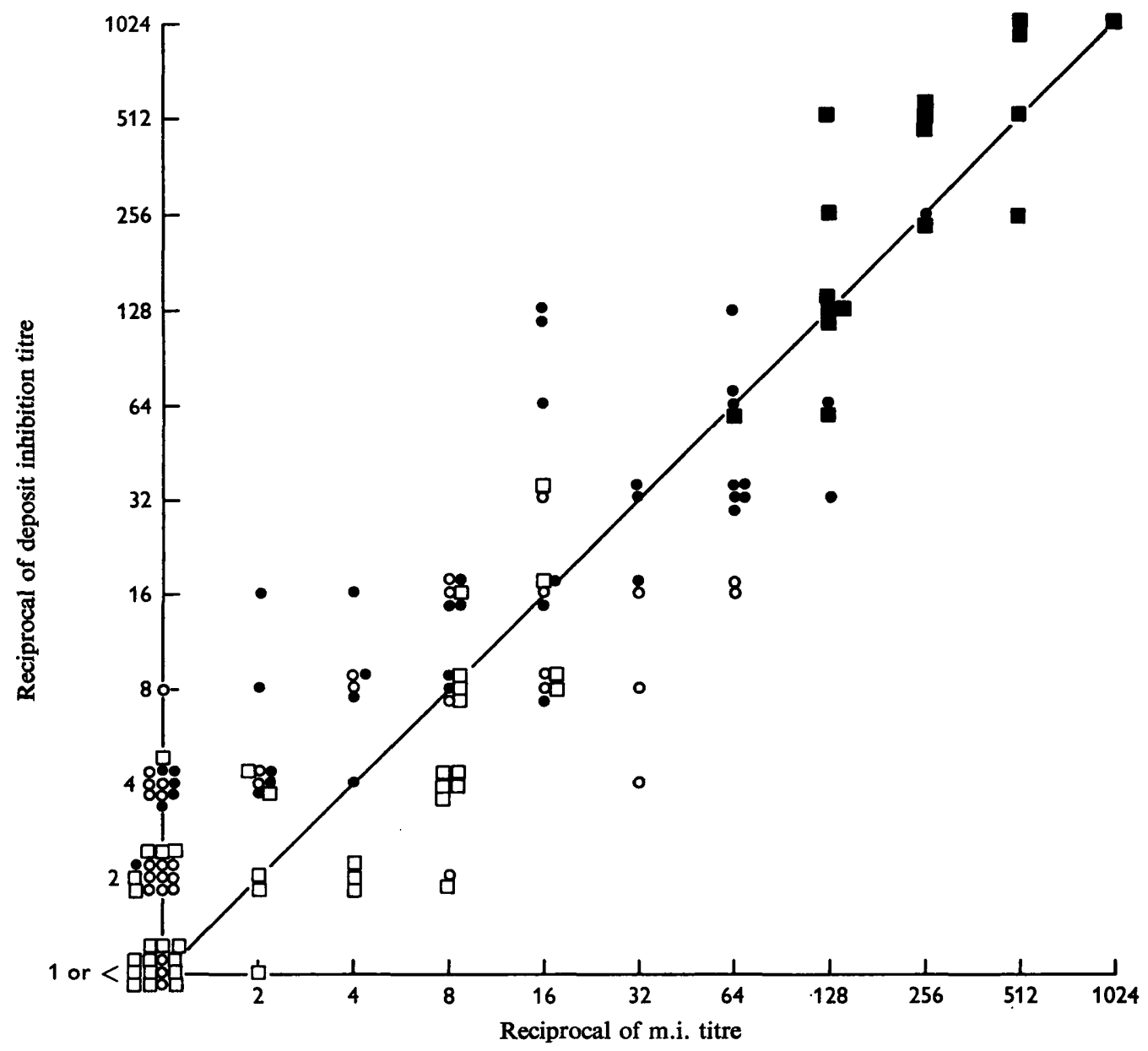

Fig. 3. Relationship between inhibition of growth deposit and inhibition of metabolism of four strains of Mycoplasma gallisepticum. O, s 6; $9, \mathrm{~T} 37 ; \square, \mathrm{T} 34, \mathrm{D}, \mathrm{A} 514$.

in cups which contained high dilutions of antiserum, sometimes occurred in cups with lower dilutions of antiserum upon continued incubation of the test. This did not happen in the presence of unheated g.p.s. Therefore, in tests performed in the absence of g.p.s., it was advisable to record the m.i. antibody titres as soon as a colour change was clearly visible, that is at a time when the $\mathrm{pH}$ of the medium containing organisms but no antiserum had changed by about half a $\mathrm{pH}$ unit. 


\section{Correlation between antibody titres measured by m.i. and g.i. in liquid medium}

Purcell et al. (1967) demonstrated a close correlation between the dilution of antiserum which inhibited a colour change in the m.i. test and the dilution which inhibited the growth in liquid medium of several mycoplasmas. An opportunity to test this correlation with strains of Mycoplasma gallisepticum arose when it was observed that, on continued incubation of some m.i. tests, buttons of deposit formed in cups which contained organisms without antiserum or organisms with high dilutions of antiserum. The deposits formed after the colour change had commenced and were produced by strains T34, T37, S6, A5969 and A5I4. Microscopic examination of some of the deposits revealed mycoplasma cells. However, it cannot be excluded that, in part, these deposits consisted of by-products of metabolism. In a number of tests with rabbit and chicken antisera (Fig. 3), m.i. antibody titres were recorded, and the occurrence of deposits also when those in cups without antiserum were first discernible; the highest dilution of antiserum which prevented the formation of a deposit was regarded as the deposit inhibition titre. A close correlation was found between m.i. titres and deposit inhibition titres which indicated that antibody measured by the $m . \mathbf{i}$. test was identical or closely related to deposit-inhibiting antibody, and thus presumably closely related to growth-inhibiting antibody.

Table 5. Disc growth inhibition tests with rabbit antisera to Mycoplasma gallisepticum strains

\begin{tabular}{|c|c|c|c|c|c|c|c|c|c|}
\hline \multirow{2}{*}{$\begin{array}{l}\text { Antiserum to } \\
\text { strain }\end{array}$} & \multicolumn{9}{|c|}{ Zone of inhibition in $\mathrm{mm}$. with mycoplasma strain } \\
\hline & T34 & T37 & A5969 & s6 & x95 & A5I 4 & JI & MG2 & C54 \\
\hline T34 & 0.2 & $I \cdot 7$ & $x \cdot 6$ & I & I & Nil & 0.5 & 0.7 & I \\
\hline T37 & $2 \cdot 6$ & 3 & $I \cdot 6$ & $I \cdot 6$ & 3 & 2 & I & Nil & I. 5 \\
\hline A5969 & $I \cdot 4$ & 3 & 2 & 2 & $3 \cdot 3$ & 0.7 & Nil & I. 5 & 0.2 \\
\hline s6 & Nil & 2 & 0.2 & $\mathrm{I} \cdot 2$ & Nil & Nil & Nil & Nil & 0.2 \\
\hline X95 & I & $4 \cdot 2$ & 0.5 & $2 \cdot 5$ & 3 & $1 \cdot 5$ & $I \cdot 7$ & 3 & $2 \cdot 7$ \\
\hline A5I4 & Nil & $1 \cdot 5$ & Nil & 0.8 & I & $3 \cdot 2$ & Nil & $I \cdot 2$ & Nil \\
\hline JI & 0.5 & 0.5 & 0.2 & Nil & $3 \cdot 2$ & Nil & 8 & $2 \cdot 5$ & $2 \cdot 2$ \\
\hline MG2 & Nil & Nil & Nil & Nil & 0.7 & 0.2 & I & $I \cdot 7$ & Nil \\
\hline
\end{tabular}

\section{Disc g.i. tests with rabbit antisera}

Most of the rabbit antisera inhibited the development of colonies of most of the strains (Table 5). Sometimes, however, colony development although inhibited by one antiserum was not necessarily inhibited by an antiserum against another strain. Indeed, only strain X95 antiserum inhibited the development of colonies of all the strains. It was possible to differentiate strain JI from the other strains; JI antiserum inhibited the development of colonies of its homologous strain to a much greater extent than it inhibited colony-formation by the heterologous strains. This apart, it was not possible to distinguish between the other mycoplasma strains on the basis of the disc g.i. test. Although the results of m.i. and g.i. tests in liquid media were comparable, there was poor correlation between the results of $\mathrm{m} . \mathrm{i}$. and disc g.i. tests since some antisera with high m.i. titres did not produce zones of inhibition. 


\section{DISCUSSION}

The results of m.i. tests with rabbit antisera showed minor antigenic differences between Mycoplasma gallisepticum strains and they may be divided into at least three subtypes within this serotype. This conclusion is valid even though the organisms of each strain used as inoculum in the tests were not harvested at the same stage of growth. The development of antibody, as measured by the m.i. test, was poorer in turkeys, and even more so in chickens, than in rabbits. However, to some extent the results observed with chicken and turkey antisera were in keeping with those observed with rabbit antisera. Thus, when strains A5I4, JI, MG2 and C54 were used to measure antibody in rabbit antisera the titres were low, and the same strains failed, in the majority of instances, to detect antibody in chicken or turkey antisera. This correlation was not complete, however, because high titres of antibody were demonstrated in rabbit antisera by using strain $\mathrm{x} 95$, but it sometimes failed to detect antibody in chicken or turkey antisera. It would be reasonable to assume that the most suitable mycoplasma strain to use for detecting antibody in chicken and turkey sera was that used to inoculate the birds. However, antibody was often only detectable by using a heterologous strain and it is clear that the choice of the mycoplasma strain for inoculum in the m.i. test is of fundamental importance for successful detection of antibody in chicken and turkey sera. The fact that birds vary widely in their antibody response to a single strain indicates that the sera of a large number of birds from a flock should be examined in order to obtain a realistic picture of the antibody status of the flock as a whole.

It is known that the effect of additional unheated g.p.s. in the m.i. test may be threefold. First, it may itself inhibit mycoplasma growth as reported previously for different mycoplasma serotypes (Taylor-Robinson et al. 1966), but its variable effect upon different strains within a serotype has not been reported. The Mycoplasma gallisepticum strains most inhibited by unheated g.p.s. were those most useful for detection of m.i. antibody, which suggests that the inhibitory effect of unheated g.p.s. might be due to it containing antibody. Contrary to this idea is the fact that g.p.s. heated at $56^{\circ}$ was not inhibitory. It is possible, however, that antibody in the g.p.s. is only active in the presence of heat-labile complement factors. Secondly, unheated g.p.s. may stabilize the m.i. titre so that it does not decrease on continued incubation of the test (Taylor-Robinson et al. 1966; Purcell et al. 1967); this was observed in some of the present experiments. Thirdly, unheated g.p.s. may enhance the specific inhibitory activity of an antiserum (Taylor-Robinson et al. 1966; Purcell et al. 1967; Fallon \& Jackson, 1967). Indeed, Barker \& Patt (1967) found that the addition of unheated g.p.s. was necessary to inhibit the growth of a strain of $M$. gallisepticum by antiserum. In most of our tests additional unheated g.p.s. did not increase but sometimes decreased the m.i. titre. It is possible that the unheated horse serum in the medium contained sufficient of the required accessory factor.

Dinter, Danielsson \& Bakos (1965), and Hayflick \& Stanbridge (1967) experienced difficulties in studying Mycoplasma hyorhinis with the disc g.i. technique. Likewise we encountered problems, since a rabbit antiserum which inhibited a strain of $M$. gallisepticum to high titre in the m.i. test did not necessarily produce a zone of inhibition on agar. However, we observed that antibody titres measured in the m.i. test correlated closely with the titres of antibody which inhibited the formation of buttons of deposit in liquid medium. It seems reasonable to assume that the deposits consisted 
mainly of mycoplasma growth. It is probable, therefore, that the difference between the results of m.i. tests and those of disc g.i. tests arises because of the difference in the tests systems and not because antisera affect growth and metabolism differently.

The disc g.i. technique is generally considered to be specific (Clyde, I964; TaylorRobinson, Canchola, Fox \& Chanock, 1964). However, Smith, Dunlop \& Strout (1966) indicated that the type of culture medium used to propagate Mycoplasma gallisepticum for antiserum production might influence the specificity of the test since they found that antiserum to medium alone was inhibitory. Although we did not examine this possibility in detail we noted that the results of m.i. tests carried out in each laboratory corresponded closely, even though the medium used to produce antigens for rabbit immunization was the same as that used for subsequent m.i. tests in one laboratory and quite different from that used for m.i. tests in the other laboratory. In addition, we have found incidentally that antisera prepared in rabbits with organisms of other mycoplasma species grown in medium containing horse serum have not produced zones of inhibition with $M$. gallisepticum. On the contrary, in the present experiments some $M$. gallisepticum antisera did not inhibit all strains even though care was taken to avoid an excess of colonies on the agar medium. Only x95 antiserum was capable of inhibiting all the strains tested. It is clear that antiserum prepared against a single strain may be inadequate in a diagnostic scheme.

We thank Mrs S. Beveridge, Miss J. A. Herring and Miss E. Witney for excellent technical assistance and Dr D. A. J. Tyrrell and Dr A. J. Beale for helpful comments on the manuscript.

\section{REFEREN CES}

AdLER, H. E. (1953). Preliminary report on the slide agglutination test for pleuropneumonia-like agents associated with infectious sinusitis of turkeys and chronic respiratory disease of chickens. SWest. Vet. 6, 362.

BARKER, L. F. \& PATT, J. K. (1967). Role of complement in immune inactivation of Mycoplasma gallisepticum. J. Bact. 94, 403.

CLYDE, W. A. JUN. (1964). Mycoplasma species identification based upon growth inhibition by specific antisera. J. Immunol. 92, 958.

Dierks, R. E., Newman, J. A. \& Pomeroy, B. S. (1967). Characterization of avian Mycoplasma. Ann. N.Y. Acad. Sci. 143, 170.

DINTER, Z., DANIELSSON, D. \& BAKOS, K. (1965). Differentiation of porcine mycoplasma strains. J. gen. Microbiol. 4I, 77.

EDWARD, D. G. ff. \& KANAREK, A. D. (1960). Organisms of the pleuropneumonia group of avian origin: their classification into species. Ann. N.Y. Acad. Sci. 79, 696.

FABRICANT, J. (1960). Serological studies of avian pleuropneumonia-like organisms (PPLO) with Edward's technique. Avian Dis. 4, 505.

FALLON, R. J. \& JACKSON, D. K. (1967). The relationship between a rodent mycoplasma, Mycoplasma pulmonis, and certain mycoplasmas isolated from tissue cultures inoculated with material from patients with leukaemia. Lab. Anim. 1, 55.

HayfuICK, L. (1965). Tissue cultures and mycoplasmas. Texas Rep. Biol. Med. 23, (suppl I), 285.

HAYFliCK, L. \& STANBRIDGe, E. (1967). Isolation and identification of Mycoplasma from human clinical materials. Ann. N.Y. Acad. Sci. 143, 608.

JungherR, E. L., LuginbuHL, R. E. \& JACOBS, R. E. (1953). Pathology and serology of air sac infection. Proc. Am. vet. med. Ass. p. 303.

MANCHEE, R. J. \& TAYLOR-ROBINSON, D. (1968). Haemadsorption and haemagglutination by mycoplasmas. J. gen. Microbiol. 50, 465.

NewNHAM, A. G. (1964). The haemagglutination-inhibition (HI) test and a study of its use in experimental avian respiratory mycoplasmosis. Res. vet. Sci. 5, 245. 
Purcell, R. H., Wong, D., Chanock, R. M., Taylor-Robinson, D., Canchola, J. \& Valdesuso, J. (1967). Significance of antibody to Mycoplasma as measured by metabolic-inhibition techniques. Ann. N.Y. Acad. Sci. 143, 664 .

SMTth, S. C., Dunlop, W. R. \& Strout, R. G. (1966). Effect of culture medium on antigenic structure of Mycoplasma. Avian Dis. ro, 173.

TAYLOR-Robinson, D. \& PURCELl, R. H. (I966). Mycoplasmas of the human urogenital tract and oropharynx and their possible role in disease: a review with some recent observations. Proc. roy. Soc. Med. 59, $1 \mathrm{I} 2$.

Taylor-Robinson, D., Canchola, J., Fox, H. \& Chanock, R. M. (1964). A newly identified oral mycoplasma (M. orale) and its relationship to other human mycoplasmas. Am. J. Hyg. 8o, 135 .

Taylor-Robinson, D., Purcell, R. H., Wong, D. C. \& Chanock, R. M. (I966). A colour test for the measurement of antibody to certain mycoplasma species based upon the inhibition of acid production. J. Hyg., Cambs. 64, 9I. 